\title{
A UTILIZAÇÃO DE ARTIGOS CIENTÍFICOS NA EXECUÇÃO DE PROJETOS DE EDUCAÇÃO AMBIENTAL: A MICROBACIA HIDROGRÁFICA DO CÓRREGO IMBIRUSSU, CAMPO GRANDE (MS)
}

\author{
Rennan Vilhena Pirajá ${ }^{1}$ \\ Arão Davi Oliveira Davi Oliveira ${ }^{2}$
}

Resumo: Este artigo tem por objetivo propor uma metodologia para elaboração de projetos de Educação Ambiental (EA) para escola regular a partir de artigos científicos que apontem impactos ambientais em microbacias hidrográficas urbanas. Apontar a fundamentação teórica e legal para planejar e executar projetos de EA em escola regular a partir de conhecimentos científicos. Utilizamos a pedagogia crítica de Paulo Freire como fio condutor dessa pesquisa, tendo em vista que seus estudos nos auxiliam a pensar numa perspectiva de autonomia cidadã, que propõe a educação libertadora, no sentido de que podemos transformar a realidade que nos rodeia. Sendo assim, socializamos conhecimentos científicos publicados em artigos científicos na comunidade escolar através de projeto de EA. Os resultados alcançados apontam uma multiplicação das possibilidades de metodologias ambientais existentes para elaboração e execução de práticas educativas em comunidades que habitam áreas de microbacias hidrográficas impactadas através da escola. Constatamos que existem legislações suficientes para fundamentar e executar projetos de EA em escolas. Percebemos que a utilização da metodologia desenvolvida neste artigo foi relevante para a preservação do meio ambiente, tendo em vista que promovemos a aproximação de estudantes aos conhecimentos científicos produzidos e publicados em periódicos sobre o meio ambiente no qual estão inseridos, permitindo que os estudantes ressignificassem seu entendimento e prática socioambiental.

Palavras-chave: Educação Ambiental; Metodologias Ambientais; Microbacias Hidrográficas.

1Uniderp - Anhanguera. E-mail: rennanvilhena345@gmail.com

2Universidade Católica Dom Bosco. E-mail: adodavi@gmail.com

Revbea, São Paulo, V. 13, № 4: 355-368, 2018.

revista brasileira

educação ambiental 


\section{Introdução}

A microbacia hidrográfica do córrego Imbirussu, localizada na porção oeste da Cidade de Campo Grande, Mato Grosso do Sul, vem sendo impactada pela dinâmica urbana associada a um núcleo industrial, o que vem ocasionando impactos ambientais diversos, transformando a área em um laboratório de pesquisas (PIRAJÁ; SILVA, 2014).

Através de levantamentos bibliográficos e de estudos utilizando imagens de satélites e geoprocessamento da área, além de visitas in-loco, Pirajá e Silva (2014) concluíram que grande parte dos problemas ambientais estão relacionados a enchentes e inundações, além de poluição, devido às atividades de origem antrópica e os processos de uso e ocupação do solo, no qual sua porção à montante é ocupada pela área urbana, por um polo empresarial e um distrito industrial.

O projeto justifica-se pelos impactos ambientais detectados na microbacia hidrográfica do Imbirussu, ligados a enchentes e inundações, poluição hídrica e assoreamento causado pelo descarte de resíduos sólidos que junto com os sedimentos chegam à calha do córrego Imbirussu; e pela necessidade fomentar consciência ambiental nos alunos das escolas públicas da região a fim de formar multiplicadores de iniciativas sustentáveis a partir do entendimento da dinâmica de bacias hidrográficas.

Portanto, fez-se necessário um trabalho de Educação Ambiental junto à comunidade que habita o entorno do córrego. Pois, concordamos que a escola tem um papel preponderante na difusão e construção de conhecimentos ambientais à sociedade, assim sendo, é necessário que o professor inicie seu trabalho com temas ambientais oriundos do contexto socioambiental do aluno, promovendo questionamentos e soluções para as problemáticas apresentadas (FERREIRA, 2015).

Nesse sentido, esse artigo tem como objetivos propor uma metodologia para utilização de artigos científicos que apontam impactos ambientais em microbacias hidrográficas na execução de projetos de EA na comunidade da região da bacia estudada. Assim como, apontar a fundamentação teórica e legal para o planejamento e execução de projetos de EA em escolas a partir de conhecimentos científicos publicados na forma de artigo científico.

Este artigo está dividido em três seções: na primeira abordaremos a microbacia do Imbirussu localizada no município de campo grande MS, mapeando os impactos ambientais e suas características morfométrica expostos no artigo de Pirajá e Silva (2014) que serviu de base para o desenvolvimento da pesquisa. $\mathrm{Na}$ segunda seção foram apontadas as legislações e acordos internacionais e nacionais que fundamentam teórica e legalmente a elaboração e execução de projetos de Educação Ambiental para a comunidade escolar. Por fim, propomos uma metodologia que possibilita a utilização de artigos científico que apontam impactos ambientais em microbacias hidrográficas na execução do projeto de Educação Ambiental para comunidade da região de uma bacia estudada.

Revbea, São Paulo, V. 13, № 4: 355-368, 2018. 


\section{O estudo da microbacia do Imbirussu, Campo Grande (MS)}

A microbacia hidrográfica do Imbirussu está localizada na porção oeste da Cidade de Campo Grande - MS (Figura 1). Sua delimitação, no perímetro urbano abrange cinco bairros (José Abrão, Panamá, Popular, Nova Campo Grande e Núcleo Industrial) e parte de sete outros bairros (Nasser, Santo Amaro, Santo Antônio, Sobrinho, Taveirópolis, São Conrado e Caiobá) além da área rural fora do perímetro urbano. (PIRAJÁ; SILVA, 2014).

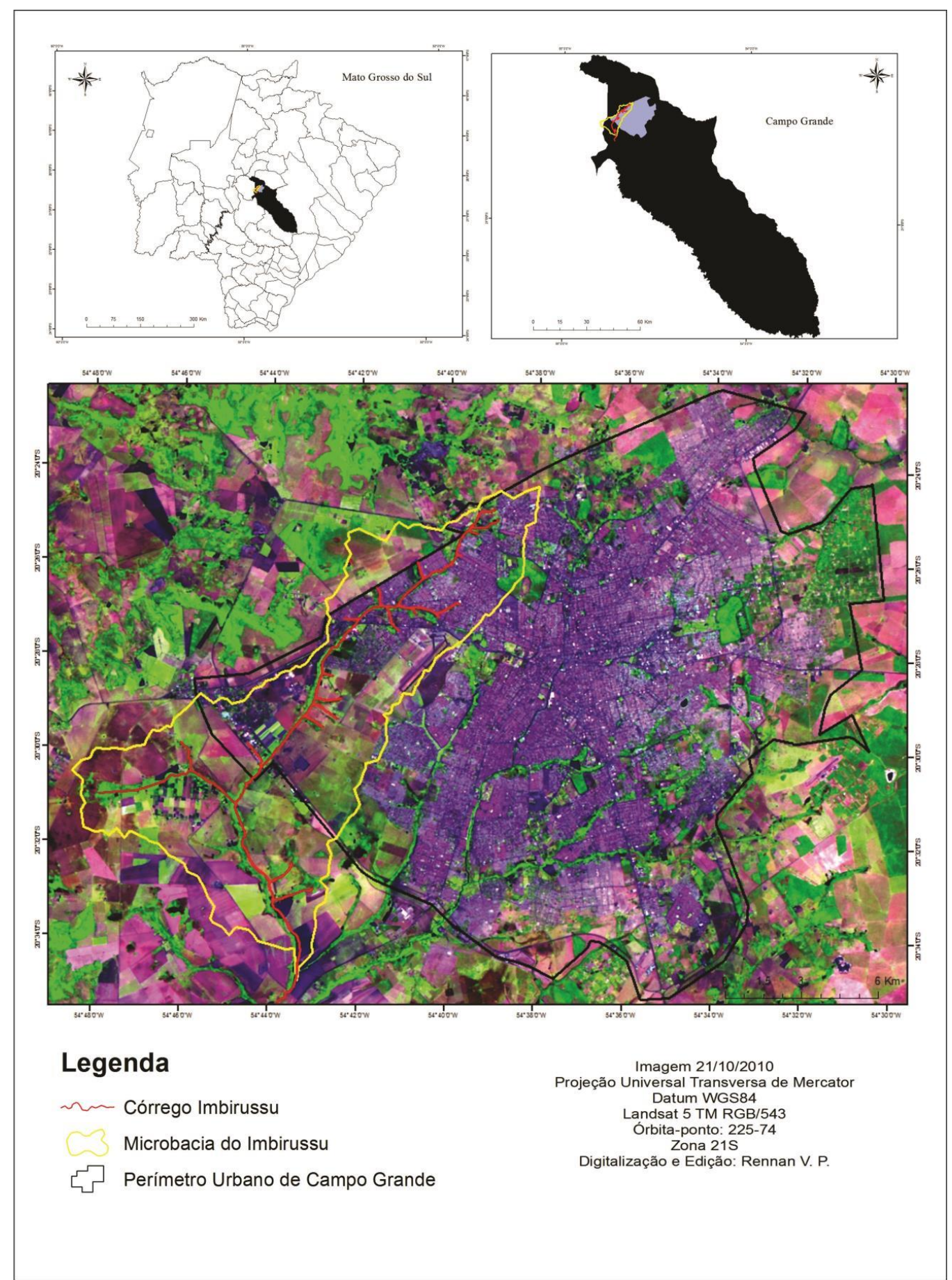

Figura 1: Bacia Hidrográfica do córrego Imbirussu. Fonte: Pirajá e Silva (2014).

Revbea, São Paulo, V. 13, № 4: 355-368, 2018. 
O córrego Imbirussu possui duas nascentes, ambas no perímetro urbano, a principal nascente forma uma lagoa localizada dentro de um condomínio residencial e a outra aflora formando uma área úmida, devido essas localizações.

Conforme levantamento realizado por Antônio (2012) sobre as políticas públicas no atendimento as famílias atingidas pelas enchentes e inundações na região do Imbirussu - Campo Grande/MS (2007-2012) concluiu que 45\% dos episódios de enchentes e inundações registrados na área urbana da cidade de Campo Grande ocorreram na região do Imbirussu.

Segundo a PLANURB (1991) a forma como foi ocupada à região da microbacia do Imbirussu, assim como, as características do relevo e solo da região são fatores preponderantes para dificultar o escoamento das águas pluviais e servidas nas áreas urbanizadas de baixa declividade o que vem provocando inundações na região.

Através dos levantamentos bibliográficos e de estudos utilizando imagens de satélites e geoprocessamento da área, além de visitas in-loco, Pirajá e Silva (2014) puderam concluir que é uma bacia bastante impactada, com problemas relacionados a enchentes e inundações, além de poluição, devido às atividades de origem antrópica e os processos de uso e ocupação do solo, no qual sua porção à montante é ocupada pela área urbana, por um polo empresarial e um distrito industrial.

Este tipo de impacto ambiental pode ser interpretado pela forma de ocupação onde parte dos canais da rede de drenagem foi aterrada devido à urbanização sem 0 planejamento eficiente. A predominância de declividade praticamente plana da bacia propicia 0 índice de permeabilização das águas das chuvas no solo, no entanto, devido à ocupação urbana, aceleram o escoamento superficial diminuindo o tempo de concentração das águas nas calhas dos canais e fazem a convergência do fluxo de água para a confluência dos córregos Serradinho e Imbirussu, o qual não consegue dar vazão a grande quantidade de água recebida (PIRAJÁ; SILVA, 2014).

No perímetro urbano da cidade de Campo Grande encontramos onze micro bacias, todas contribuintes do Rio Anhanduí (Figura 2). Desenvolvemos este projeto de EA na Comunidade Escolar da região urbana do Imbirussu por possuir o maior percentual de enchente em comparação às outras regiões de Campo Grande.

Utilizando esses conhecimentos podemos propor uma ação educativa, pois a Educação Ambiental permite que a escola entre em contato com o campo ambiental, promovendo reflexões, metodologias e experiências práticas que têm por objetivo construir conhecimentos e valores ecológicos na atual e nas futuras gerações. 


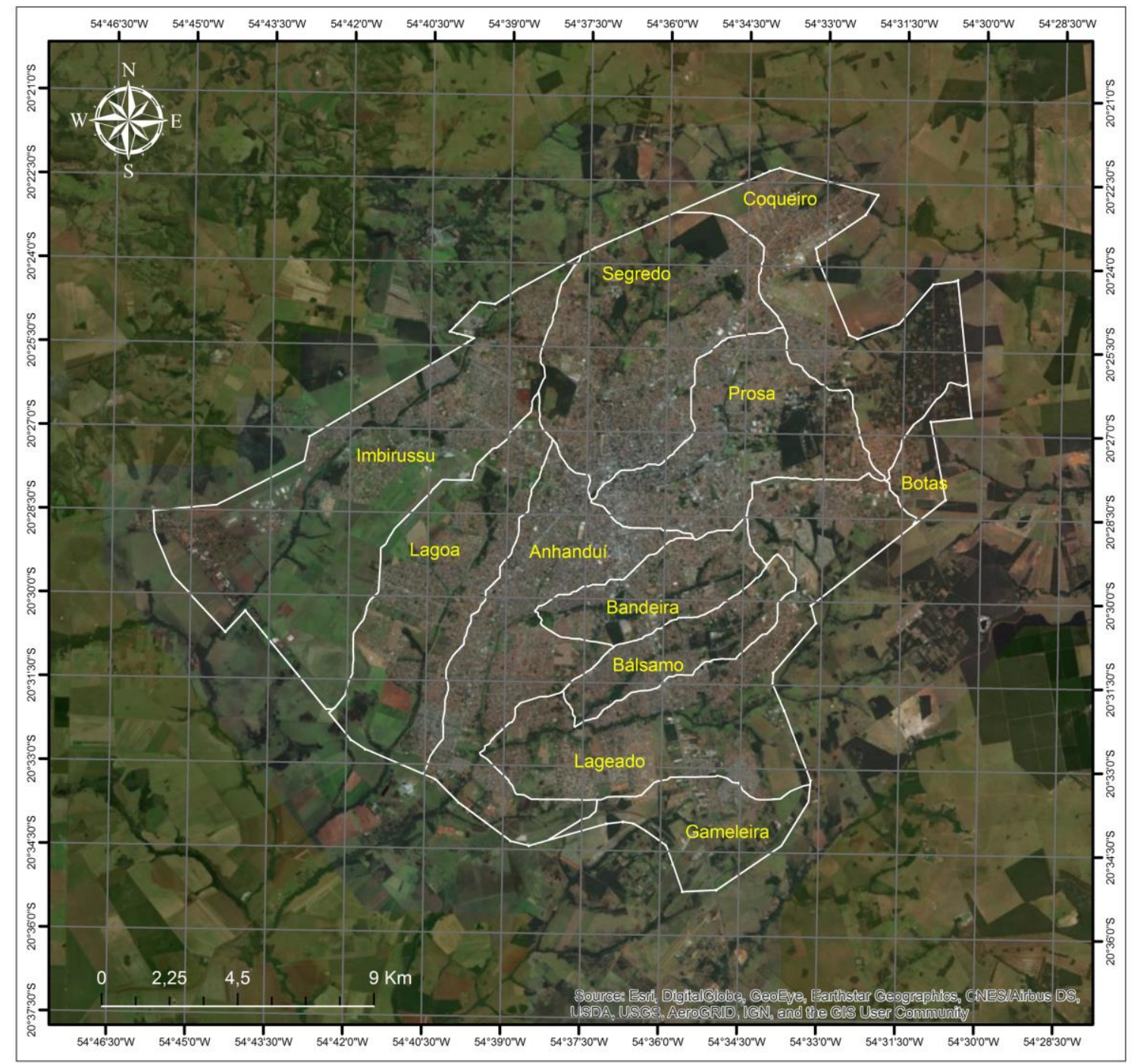

Figura 2: Mapa das 11 microbacias situadas dentro do perímetro urbano de Campo Grande e que contribuem para a formação do Rio Anhanduí. As microbacias são utilizadas pela prefeitura da cidade como unidades de planejamento para a gestão urbana. Fonte: Org. pelos autores (ARCGIS, 2018).

\section{Fundamentos para uma ação educativa}

Balizados por uma proposta de educação libertadora inspirada na pedagogia crítica que tem como referência maior Paulo Freire, grande educador brasileiro, que propôs em seus estudos uma ação transformadora da realidade que ora encontramos pensando e agindo de forma autônoma.

Transpondo isso para a Educação Ambiental é importante que a escola promova possibilidades de desenvolvimento cognitivo integrado as questões sociais, pelo incentivo da reflexão e busca de soluções de questões percebidas pelos próprios alunos, através da observação e de inserção dos alunos em discussões das questões ambientais no seu espaço de convivência social. Alinhado com essa proposta (RUSCHEINSKY, 2002. p.79) afirma que "a busca 
constante da autonomia, como substrato do sujeito nas múltiplas dimensões, deverá ser o fator motivador mais importante da Educação Ambiental'.

Ações de sustentabilidade vêm sendo discutidas entre as nações há décadas. Principalmente após a popularização da ética ambiental por Albert Schweitzer que foi vencedor do Prêmio Nobel da Paz em 1954. Iniciava-se pelo mundo um movimento que tinha por foco reverenciar as coisas vivas, e questionava o estilo de desenvolvimento.

Nesse sentido, trinta especialistas de várias áreas se reuniram no ano de 1968, em Roma para discutir esses questionamentos, dando origem ao Clube de Roma. Outros encontros com a temática da preservação do meio ambiente foram acontecendo ao longo dos anos, os mais destacados e que marcam a história da Educação Ambiental e que originaram documentos que propõem a Educação Ambiental como políticas públicas de estado foram: Estocolmo, 1972; Tbilisi, 1977; Belgrado, 1985; Moscou, 1987; Rio, 1992; Rio + 10, Joanesburgo, 2002.

Durante a Rio/92, foram assinados tratados nos quais se reconhece a educação como ferramenta decisiva para a construção de uma consciência socialmente justa e ecologicamente equilibrada, onde os indivíduos assumam "responsabilidade individual e coletiva em níveis local, nacional e planetário".

A Educação Ambiental não pode se resumir às críticas sobre o processo de ocupação "degradante" que o homem promove na natureza, mas deve analisá-lo dentro de uma teia de relações sociais em que a prática pedagógica desenvolvida na escola é parte integrante de uma sociedade multifacetada por interesses ideológicos e culturais (TAMAIO, 2002, p. 37).

A Educação Ambiental (EA) é contemplada no art. 225, § 1ํㅡㄹ inciso VI da Constituição Federal de 1988, ao estabelecer a "promoção da Educação Ambiental em todos os níveis de ensino e a conscientização pública" (BRASIL, 2008, p. 35).

Todas as recomendações, decisões e tratados internacionais sobre o tema evidenciam a importância atribuída por lideranças de todo o mundo para a Educação Ambiental como meio indispensável para conseguir criar e aplicar formas cada vez mais sustentáveis de interação sociedade/natureza e soluções para os problemas ambientais. Evidentemente, a educação sozinha não é suficiente para mudar os rumos do planeta, mas certamente é condição necessária para isso. Nesse contexto, fica evidente a importância de educar os brasileiros para que ajam de modo responsável e com sensibilidade, conservando o ambiente saudável no presente e para o futuro. Para que saibam exigir e respeitar os direitos próprios e os de toda a comunidade, tanto local como internacional; e se modifiquem tanto interiormente, como pessoas, quanto nas suas relações com o ambiente. (BRASIL, 1998 p. 22)

Revbea, São Paulo, V. 13, № 4: 355-368, 2018. 
Concordamos com Reigota (1994, p.28) quando assegura que "o desafio da Educação Ambiental é sair da ingenuidade e conservadorismo (biológico e político) a que se viu confinada e propor alternativas sociais, considerando a complexidade das relações humanas e ambientais". Pois, para Reigota, (1994, p.10) a transmissão de saberes ecológico não garante uma Educação Ambiental útil à sociedade, sendo assim seria mais uma prática pedagógica desconectada com a realidade e as demandas socioambientais, trata-se de uma educação que visa não só a utilização racional dos recursos naturais, (...), mas basicamente a participação dos cidadãos nas discussões e decisões sobre a questão ambiental.

Pois, para Reigota:

A Educação Ambiental escolar deve-se enfatizar o estudo do meio ambiente onde vive 0 aluno e a aluna, procurando levantar os principais problemas cotidianos, as contribuições da ciência, da arte, dos saberes populares, enfim, os conhecimentos necessários e as possibilidades concretas para a solução deles (REIGOTA, 1994, p. 46).

Os idealizadores dos Parâmetros Curriculares Nacionais - PCN no seu volume 10-4, resgatam os Princípios da Educação Ambiental de Tbilisi,1977 que indicam como o tema da Educação Ambiental deve ser trabalhado nas escolas: "aplicar um enfoque interdisciplinar, aproveitando o conteúdo específico de cada área, de modo que se consiga uma perspectiva global da questão ambiental' (BRASIL, 1998. p.230).

Para os idealizadores dos PCN a solução dos problemas ambientais tem sido considerada cada vez mais urgente para garantir o futuro da humanidade e depende da relação que se estabelece entre sociedade/natureza, tanto na dimensão coletiva quanto na individual (BRASIL, 1998).

Essa consciência já chegou à escola e muitas iniciativas têm sido tomadas em torno dessa questão, por educadores de todo o país. Por essas razões, vê-se a importância de incluir Meio Ambiente nos currículos escolares como tema transversal, permeando toda prática educacional. É fundamental, na sua abordagem, considerar os aspectos físicos e biológicos e, principalmente, os modo de interação do ser humano com a natureza, por meio de suas relações sociais, do trabalho, da ciência, da arte e da tecnologia (BRASIL, 1998. p.169).

Sobre a legislação de EA brasileira, podemos destacar a Lei oㅜ 9.795 de 27.04.1999, que instituiu a Política Nacional de Educação Ambiental (PNEA). Seu art. 1ำ dispõe: Educação Ambiental são os processos por meio dos quais 0 indivíduo e a coletividade constroem valores sociais, 
conhecimentos, habilidades, atitudes e competências voltadas para a conservação do meio ambiente, bem de uso comum do povo, essencial à sadia qualidade de vida e sua sustentabilidade (BRASIL, 1999).

O ambiente urbano é "resultado de aglomerações localizadas em ambientes naturais transformados, e que para a sua sobrevivência e desenvolvimento necessitam dos recursos do ambiente natural' (PHILIPPI JR, 2005, p. 3).

Podemos dizer que as práticas educativas devem propor uma observação sensível e crítica do ambiente já que a práticas da pedagogia tradicional não veem possibilitado aos estudantes agirem como sujeitos cognoscentes, ou seja, participarem da construção da própria aprendizagem. Queremos um aluno observador, questionador, crítico, reflexivo, cooperativo, íntegro e ético. Nesse sentido, a EA pode oferecer elementos importantes para a formação desses sujeitos.

\section{Utilização de artigos científico na execução do projeto de Educação Ambiental}

As geociências não enfrentam o mesmo problema que as ciências sociais em desenvolver conhecimentos que sirvam como instrumentos para compreender e intervir sobre processos que têm interferência sobre a vida cotidiana.

Nesta seção desenvolveremos uma metodologia para utilização de conhecimentos produzidos em um estudo de bacias hidrográficas na elaboração e execução de um projeto de Educação Ambiental. Aplicando-o na comunidade residente na região da bacia estudada.

A aprendizagem e o conhecimento exploram os limites da escola e estão submetidas à outra lógica (TRISTÃO, 2002). Sendo assim, é importante que a comunidade escolar possibilite outros contextos cognitivos, em situações de aprendizagem diferentes das de sala de aula, como no exemplo do plantio de mudas de árvores na mata ciliar do córrego que eles veem todos os dias ao ir para escola. Um contexto de aprendizagem que possibilite a integração dos saberes científicos com uma atuação ética de cidadania preocupada com a natureza.

A execução de projetos de EA é uma forma de mitigar as causas de impactos ambientais e despertar consciência ambiental nos estudantes envolvidos através de informações sobre a biodiversidade local (Figura 6) e práticas ambientais sustentáveis para que os mesmos possam ser multiplicadores da importância da preservação da bacia hidrográfica para o ambiente no qual habitam.

Pode-se utilizar a pedagogia crítica de Paulo Freire como fio condutor da execução do projeto de EA, pois para esse autor é primordial utilizar os conhecimento do sujeito no ambiente em que vive promovendo a integração 
dos conhecimentos locais com os macros oferecidos pela sociedade como um todo.

É interessante observar a existência de possíveis parceiros para desenvolver 0 trabalho em escolas, que pode ser ONGs, Universidades, Secretarias de Estado ou do Município, Associações e outros.

Nesse sentido, firmamos acordo de cooperação com o Centro de Educação Ambiental Odilza Fernandes Bittar - CEA Imbirussu e com a Escola Municipal Carlos Vilhalva ambos situados na avenida que margeia o córrego Imbirussu. O CEA Imbirussu participou da coordenação do plantio de setenta mudas de árvores nativas do cerrado cedidas pela Secretaria de infraestrutura e urbanização - SEINTRA, e plantadas pelos estudantes. Conforme verificado por Pirajá e Silva (2014) os impactos causados por descarte de resíduos sólidos de forma indevida comprometem a vegetação da mata ciliar no trecho urbano do córrego.

Em nossa proposta metodológica o projeto deve ser executado em duas etapas com a participação de duas turmas de sextos anos do período matutino de forma interdisciplinar com os professores das disciplinas de Geografia e Ciências conforme recomenda os PCN:

Para que os alunos construam a visão da globalidade das questões ambientais, é necessário que cada profissional de ensino, mesmo especialista em determinada área do conhecimento, seja um dos agentes da interdisciplinaridade que o tema exige. A riqueza do trabalho será maior se os professores de todas as disciplinas discutirem e, apesar de todo tipo de dificuldades, encontrarem elos para desenvolver um trabalho conjunto. Essa interdisciplinaridade pode ser buscada por meio de uma estruturação institucional da escola, ou da organização curricular, mas requer, necessariamente, a procura da superação da visão fragmentada do conhecimento pelos professores especialistas (BRASIL, 1998, p. 193).

$\mathrm{Na}$ primeira etapa, realizamos em conjunto com o CEA e com os professores de Geografia e Ciências palestras no auditório da Escola com turmas de sextos anos. Não existe a obrigatoriedade de se aplicar o projeto a turmas de sextos anos, porém deve-se adaptar o conteúdo e abordagem a faixa etária dos estudantes.

Na palestra é importante que seja demonstrada a localização espacial da bacia hidrográfica trabalhada (em nosso caso a do Imbirussu no município de Campo Grande - MS), assim como a localização da escola onde o projeto for aplicado. Para explicação da dinâmica da bacia hidrográfica pode-se utilizar dos mapas georeferenciados e imagens de satélite do sitio Google Earth, ou os disponibilizados no artigo que subsidia o projeto de EA. Baseado no artigo deve-se apontar, também, os impactos provocados pelo descarte incorreto de 
resíduos sólidos, assim como, a rica biodiversidade ainda existente na mata de galeria do córrego. Para isso, é recomendável a apresentação de fotografias de pontos de assoreamento e poluição no córrego e, também, da biodiversidade existente dentro do ambiente urbano (Figuras 3 e 4).

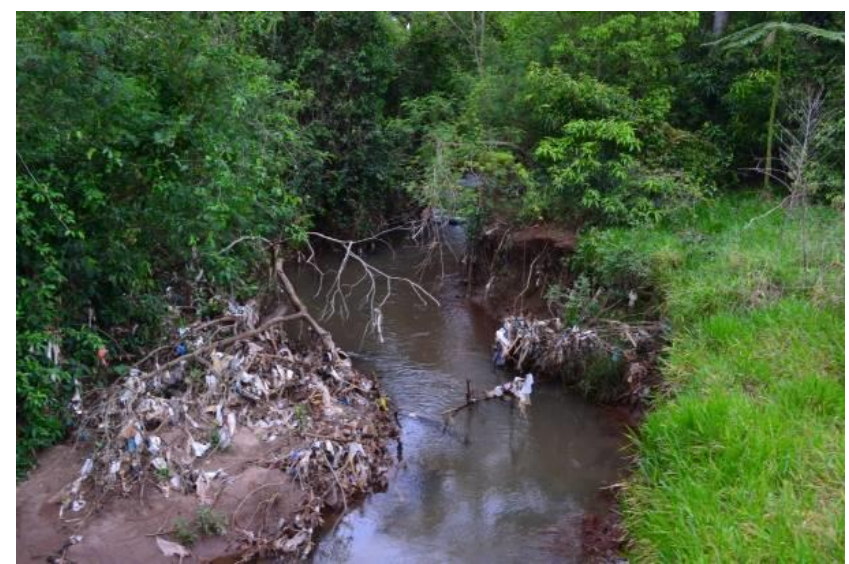

Figura 3: Trecho do córrego Imbirussu dentro do Centro de Educação Ambiental (CEA) Fonte: Acervo fotográfico dos autores.

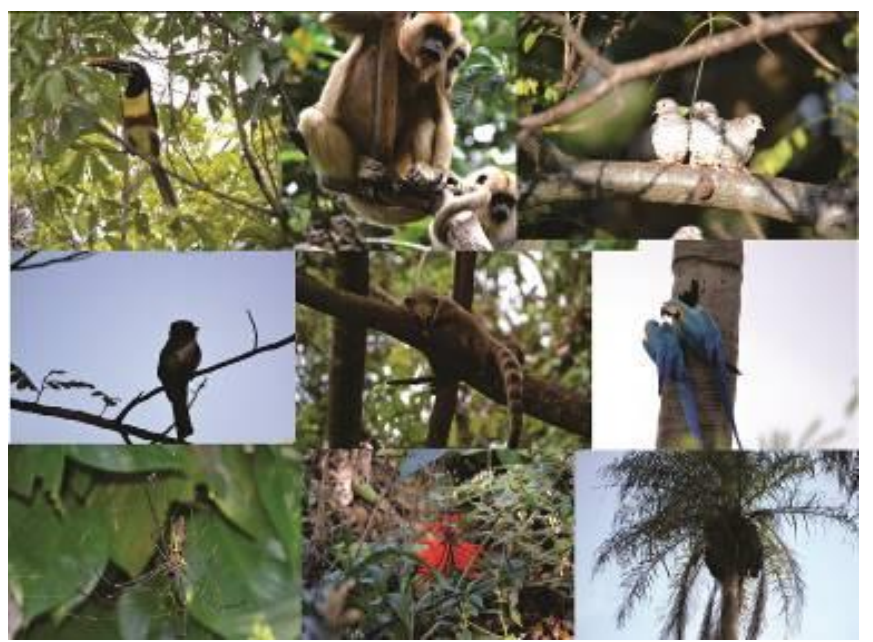

Figura 4: Exemplares da biodiversidade encontrados na bacia hidrográfica do córrego Imbirussu, Campo Grande - MS. Fonte: Acervo fotográfico dos autores.

Optamos por abordar a correta forma de descarte de resíduos sólidos enfatizando de forma didática os conceitos dos 3R's (Reduzir, Reutilizar e Reciclar) e a importância de se ter uma postura de preservação do meio ambiente.

Durante nossa palestra foram exibidas imagens com a fauna e a flora que pertence à reserva ambiental do córrego Imbirussu e sua importância na manutenção do ecossistema e a importância da arborização urbana e como todas essas ações possibilitarão uma mitigação no processo de inundações que ocorrem nesta região. 
Mas, partimos do pressuposto de que múltiplos e variados aspectos interferem na aprendizagem e convivem, ao mesmo tempo, com o caos e com a ordem, no movimento ordem/desordem /organização. Dessa maneira é até possível dizer que a educação é auto-eco-organizativa, no sentido de que uma dimensão é atravessada por várias outras dimensões, assim como o sujeito é atravessado por várias identidades (TRISTÃO, 2002. p. 172).

$\mathrm{Na}$ segunda fase executam-se na prática os conhecimentos adquiridos na primeira fase visando mitigar as causas de impactos percebidas pelos autores do artigo científico. Objetivando articular a conscientização ambiental através da prática e poder provocar um envolvimento dos alunos no processo de desenvolvimento do conhecimento da natureza que o cerca, onde a cidadania crítica pode ser exercida. Essa experiência será, certamente, repassada aos parentes, amigos e vizinhos.

Assim, foram plantadas pelos alunos setenta mudas de espécies de árvores nativas do Cerrado (Figura 5) no entorno do córrego onde foi detectado o principal ponto inundação conforme Pirajá e Silva (2014) (Figura 6), no sentido de colaborar com a recomposição da mata ciliar do córrego com apoio e supervisão do CEA Imbirussu.

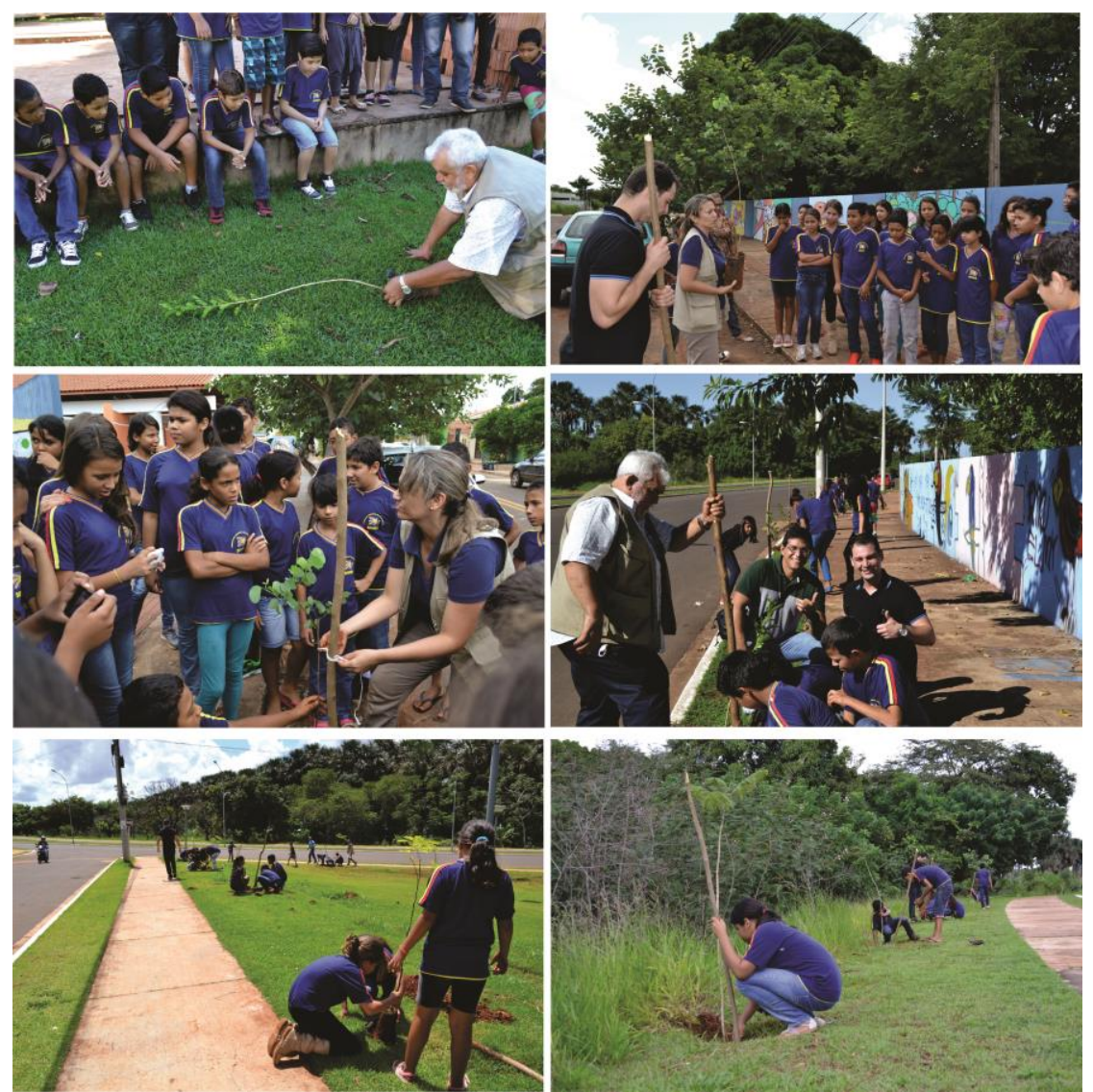

Figura 5: Realização dos plantios pelos alunos. Fonte: Acervo dos autores.

Revbea, São Paulo, V. 13, № 4: 355-368, 2018.

revista brasileira

educação ambiental 


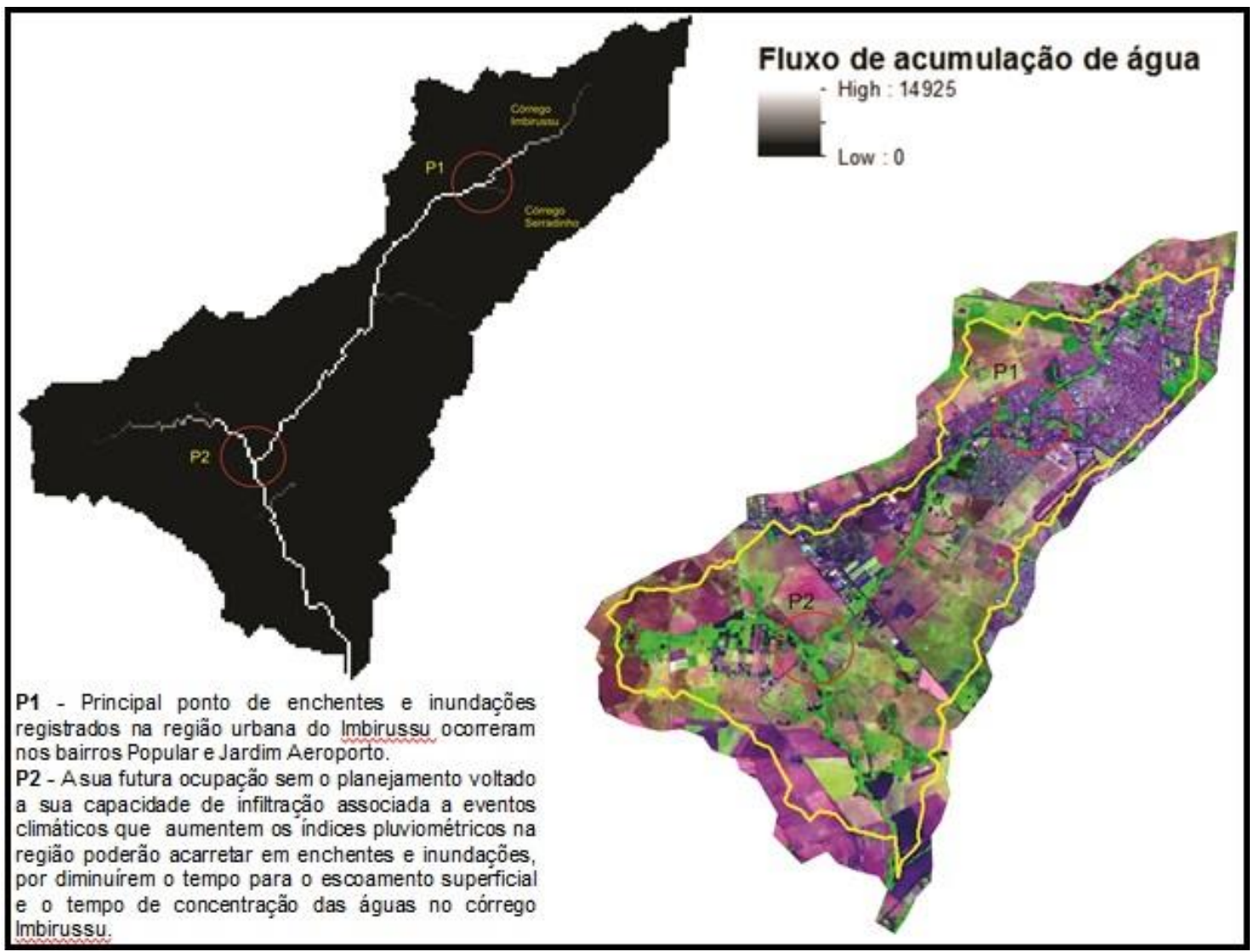

Figura 6: imagens de satélite revelam os maiores pontos de fluxo de acumulação de água do córrego Imbirussu, o P1, localizado nas proximidades do bairro Jardim Aeroporto e o P2, localizado fora do perímetro urbano, na zona rural. Fonte: Pirajá e Silva (2014).

A articulação entre o conhecimento e a ação, o primeiro orientando a ação e sendo, por sua vez, redimensionado a partir dos resultados dessa mesma ação, é um aspecto fundamental do processo de construção do conhecimento, que se encontra presente no conceito de práxis-ação e reflexão como constituintes da compreensão transformadora da realidade (SAITO, 2002. p. 53).

Na proposta de projeto de EA oferecido as escolas é importante que o autor alcance os seguintes resultados: gerar uma conscientização dos alunos para importância da preservação do meio ambiente em que vive; promover um aprendizado sobre a função da mata ciliar na contenção do solo e na manutenção da biodiversidade existente na região do córrego; possibilitar aos alunos identificar os sintomas e as causas reais dos problemas ambientais (tanto as locais quanto as mais amplas, de acordo com as possibilidades de compreensão em cada fase do ensino); mostrar a importância do correto descarte dos resíduos sólidos; e, tornar os estudantes colaboradores da recomposição da mata ciliar, da arborização urbana, transformando-os em agentes disseminadores de práticas sustentáveis. 


\section{Considerações finais}

Baseado no artigo científico de Pirajá e Silva (2014) podemos extrair elementos precisos dos impactos ambientais que essa bacia é acometida para propor uma ação de intervenção educativa, através de projeto de Educação Ambiental oferecido em uma escola da região da Bacia hidrográfica pesquisada.

A quantidade de leis e acordos internacionais sobre as questões ambientais, assim como o apelo legal paro o incentivo da conscientização da sociedade para práticas sustentáveis, através da Educação Ambiental dão suporte suficiente para a elaboração e execução de projetos de EA.

Neste artigo socializamos uma metodologia de valorização de trabalhos científicos na área do meio ambiente expandindo o resultado de pesquisas para a comunidade escolar existente no lócus da pesquisa.

Percebemos que utilização dessa metodologia foi de grande relevância para a preservação do meio ambiente, tendo em vista que promovemos a aproximação de estudantes aos conhecimentos científicos produzidos e publicados em periódicos sobre seu lócus socioambiental. Assim como, isso o faz perceber os problemas e nuances do uso e ocupação do solo e como pode interferir para mitigar possíveis causas de impactos e prevenir outros.

\section{Referências}

ANTONIO, A. L. A. Análise das políticas públicas no atendimento as famílias atingidas pelas enchentes e inundações na região do Imbirussu -Campo Grande/MS (2007-2012). 2012. 74f. Dissertação (Mestrado em Meio Ambiente e Desenvolvimento Regional) -Universidade Anhanguera -UNIDERP, Campo Grande.

[ARCGIS] ArcGIS: Software. Disponível em <http://www.esri.com/software/arcgis/index.html>. Acessado em 10 de Fevereiro de 2011.

BRASIL, Ministério da Educação. Parâmetros Curriculares Nacionais. Secretaria de Educação Fundamental. Brasília: MEC/SEF, 1998.

BRASIL, Lei n ${ }^{\circ} 9.795$, de 27 de abril de 1999. DOU. Dispõe sobre a Educação Ambiental, institui a Política Nacional de Educação Ambiental e dá outras providências.

CAMPO GRANDE. Secretaria Municipal de Meio Ambiente e Desenvolvimento Urbano - SEMADUR. Qualidade das Águas Superficiais de Campo Grande: Relatório $2010 . \quad$ Disponível em: $<$ http://www.pmcg.ms.gov.br/semadur/canaisTexto?id can=6399 >. Acesso em 14 de jun. 2014

CARVALHO, I,C.M. Educação Ambiental: a formação do sujeito ecológico. São Paulo: Cortez, 2006. 
FERREIRA, S. E. Educação Ambiental: práticas ambientais utilizando os espaços públicos na cidade de Manaus. Disponível em: $<$ http://amigosdanatureza.org.br/publicacoes/index.php/forum ambiental/article/ view/813/837> Acessado em 9 de fevereiro de 2015.

FREIRE, P. Pedagogia do Oprimido. Rio de Janeiro: Paz e Terra, 14 ${ }^{a}$ ed. 1985.

FREIRE, P. Ação Cultural para a Liberdade. Rio de Janeiro: Paz e Terra, $7^{a}$ ed. 1984.

FREIRE, P. Pedagogia da Esperança: um reencontro com a Pedagogia do Oprimido. Rio de Janeiro: Paz e Terra. 16ª ed. 2009.

PHILIPPI JR., A; PELICIONI, M. C. F. Educação Ambiental e sustentabilidade. Barueri: Manole, 2005.

LOUREIRO, C.F.B. Trajetória e Fundamentos da Educação Ambiental. São Paulo: Cortez, 2006.

PLANURB. Instituto Municipal de Planejamento Urbano. Carta geotécnica de Campo Grande-MS. 1991. Disponível em: < www.pmcg.ms.gov.br/egov/downloadFile.php id= ...> Acesso em 20 de junho.2014

REIGOTA, M. O que é Educação Ambiental. São Paulo: Brasiliense, 2009.

RUSCHEINSKY, A. (Org.). Educação Ambiental: Abordagens Múltiplas. Porto Alegre: Artmed, 2002. $183 \mathrm{p}$.

PIRAJÁ. R. V.; SILVA, M. H. S. Caracterização Morfométrica da Microbacia Hidrográfica do Córrego Imbirussu - Campo Grande, MS. Periódico Eletrônico Fórum Ambiental da Alta Paulista, v.10, n.2, p. 168-182, 2014.

REIGOTA, M. O que é Educação Ambiental. São Paulo, SP: Brasiliense, 1994.

SAITO, C. H. Política Nacional de Educação e Construção da Cidadania: Desafios Contemporâneos. In: RUSCHEINSKY, A. (Org.) Educação Ambiental: Abordagens Múltiplas. Porto Alegre: Artmed, 2002. p. 47-60.

TAMAIO, I. 0 professor na construção do conceito de natureza: uma experiência de Educação Ambiental. São Paulo: Annablume: WWF, 2002.

TRISTÃO, M. As dimensões e os desafios da Educação Ambiental na sociedade do conhecimento. In: RUSHEINSKY, A. (Org.). Educação Ambiental: abordagens múltiplas. Porto Alegre: Artmed, 2002. 